\title{
Recherches sur le diagnostic allergique de la lymphangite épizootique du cheval par l'histoplasmine
}

\author{
par MM. Ph. HILSONT et J. VERGE
}

La parenté qui, selon certains auteurs, existerait entre Histoplasma capsulatum et Cryptococcus farciminosus, nous a incités à utiliser l'histoplasmine (extrait filtré et stérile de cultures d'H. capsulatum en milieu synthétique à base d'asparagine) pour le diagnostic clinique de la lymphangite épizootique des équidés.

Nos recherches ont été réalisées à Bamako (A.O.F.), étant donné le caractère exceptionnel de la cryptococcose équine en France à l'heure actuelle. Les animaux cliniquement infectés subissaient un contrôle microscopique et l'on s'attachait à déceler l'élément spécifique par examen du pus entre lame et lamelle et mise en évidence du cryptocoque, facilement reconnaissable à sa forme, à ses extrémités en citron et surtout à sa membrane d'enveloppe de double contour.

L'histoplasmine concentrée a été, pour l'usage, diluée à $1 / 10$ au moyen de sérum physiologique et injectée par voie intradermique au niveau de la paupière inférieure, réalisant ainsi une technique absolument identique à l'épreuve palpébrale pour la détection de la morve.

La lecture des résultats a eu lieu quarante-huit heures après la sollicitation allergique. La réaction positive aurait dû se traduire, supposions-nous, par un œedème cutané plus ou moins marqué au niveau de l'injection, par une induration persistante et sensible du territoire interrogé ainsi que par des manifestations de conjonctivite muco-purulente plus ou moins étendue.
Nous avons utilisé tout d'abord, en Afrique comme en France, l'histoplasmine chez de nombreux chevaux sains, étalons ou juments, bien connus de nous et exempts de tous signes de lymphangite spécifique. Aucune réaction n'est apparue dans les heures qui suivirent le test palpébral.

Nous avons utilisé ensuite l'histoplasmine chez six chevaux et un mulet présentant des symptômes incontestés de lymphangite cryptococcique au niveau du thorax ou des membres, avec ulcérations riches en parasites.

Dans quelques cas, la réaction fut marquée, après vingt-quatre heures, par un bourrelet léger réduisant à peine la fente palpébrale et montrant une sensibilité minime à la palpation. Les signes tendaient rapidement à disparaître; de plus, l'ceil n'a manifesté à aucun moment de tendance ni au larmoiement, ni à la suppuration.

\section{Conctusions}

Dans les conditions de nos essais, l'histoplasmine, extrait stérile de cultures filtrées d'Histoplasma capsulatum, ne saurait être utilisée avec succès dans le diagnostic allergique de la lymphangite épizootique des équidés, malgré la parenté qui semble unir Histoplasma capsulatum et Cryptococcus farciminosus. 